\title{
18. MAGNETIC PROPERTIES OF LEG 37 BASALTS AND A DETERMINATION OF PALEOMAGNETIC FIELD INTENSITY
}

\author{
D.J. Dunlop and C.J. Hale, Geophysics Laboratory, University of Toronto, Toronto, Canada
}

\begin{abstract}
We report NRM, AF and thermal demagnetization, VRM, hysteresis, Curie temperature, and paleointensity data for 23 samples from DSDP Leg 37. Samples from Hole 332B have low inclinations $\left(1.5^{\circ}\right.$ to $34^{\circ}$, predominantly negative) for this latitude, whereas Site 335 samples have more normal values $\left(-42^{\circ}\right.$ to $\left.-54^{\circ}\right)$. NRM is usually stable in direction during AF demagnetization to 1000 oe and thermal demagnetization to $250^{\circ} \mathrm{C}$. In a two-month storage test, NRM changed $5^{\circ}$ or less in six samples, about $10^{\circ}$ in three samples, and $20-25^{\circ}$ in three samples. Although VRM is not large at $20^{\circ} \mathrm{C}$, it frequently increases to a spectacular peak at $75^{\circ}-100^{\circ} \mathrm{C}$, a Hopkinson effect reflecting low Curie points. The relaxation times involved would produce both accelerated viscous magnetization over the time of a polarity epoch and an enhanced axial anomaly due to the higher susceptibility of hot material rising at a mid-ocean ridge.

There is a striking correlation among NRM stability, hysteresis properties, the presence or absence of a VRM peak around $100^{\circ} \mathrm{C}$, and thermomagnetic curves. Magnetically soft samples contain coarse, multidomain titanomagnetite with a Curie point of about $200^{\circ} \mathrm{C}$. This phase is chemically stable on heating and is responsible for VRM. Magnetically hard samples contain in addition a singledomain-like phase with Curie temperature $450^{\circ}-520^{\circ} \mathrm{C}$, presumably the result of exsolution of originally homogeneous titanomagnetite. The amount of this hard phase increases two- or threefold upon heating.

Five samples were successfully studied by the Thellier-Thellier method. No meaningful data were obtained above $200^{\circ} \mathrm{C}$ because of chemical changes. The paleofield intensity estimates fall in the range 0.10 to 0.45 oe.
\end{abstract}

\section{STABLE MAGNETIZATION}

\section{AF Demagnetization of NRM}

Three samples (332B-11-4, 332B-36-3, 335-8-4) were stepwise AF demagnetized to 1000 oe using a 3-axis Schonstedt demagnetizer. Magnetizations were measured with a Digico spinner magnetometer. Data are listed in Table 1. These samples were directionally stable to 800 or 1000 oe.

Seven samples (2-1, 3-1, 11-2, 29-1, 44-6 from Hole 332B; 20-2 from Site 334; and 6-1 from Site 335) were AF demagnetized to 2500 oe and measured along a single-axis, using an instrument described by West and Dunlop (1971). Median demagnetizing fields, $\check{H}_{1 / 2}$ varied from 34 oe for 332B-11-2 to 685 oe for 335-6-1. (See Table 2 for a complete listing).

\section{Storage Test of NRM}

Twelve samples (11-1, 14-2, 17-1, 22-4, 27-2, 33-1, 462 from Hole 332B; 26-1 from Site 334; 7-1, 8-2, 10-1, $12-$ 3 from Site 335) were stored two months with the present earth's field parallel to the vertical up axis of each core. Data are tabulated in Table 3. Five
332B samples were stable (NRM changed $5^{\circ}$ or less), two were less stable (NRM changed $20^{\circ}-25^{\circ}$ ). Three 335 samples changed about $10^{\circ}$, the other $25^{\circ}$. Sample 334-26-1 was very stable in direction.

\section{Thermal Demagnetization of NRM}

After storage, the above samples were thermally demagnetized in field-free space. Measurements were made with a PAR spinner magnetometer. Heatings were in vacuum $\left(10^{-5}\right.$ torr), but irreversible chemical changes nevertheless occurred above $250^{\circ} \mathrm{C}$. Up to this temperature, NRM was generally stable in direction. Three examples are shown later in Figure 3. Complete data are tabulated in Table 4.

\section{Direction and Intensity of NRM}

NRM intensities are in the range 1000-4000 $\times 10^{-6}$ emu cm$~^{-3}$, sufficient to account for magnetic anomalies observed at the ocean surface. However, Hole 332B samples have anomalously low inclinations, $1.5^{\circ}$ to $34^{\circ}$, for their age and latitude. As expected from their location in a negative anomaly (between positive anomalies 2 and 3 ), they tend to be reversely magnet- 
TABLE 1

AF Demagnetization of DSDP Leg 37 Basalts

\begin{tabular}{crrr}
\hline A. C. Field & M $\times 10^{6}$ & D & \multicolumn{1}{c}{ I } \\
\hline 332B-11-4, 60-73 (51) DP DP & \\
\multicolumn{4}{c}{} \\
0 & 4535 & 268.0 & +8.1 \\
25 & 4365 & 264.5 & +11.3 \\
50 & 4040 & 262.6 & +15.3 \\
75 & 3400 & 264.7 & +17.4 \\
100 & 2880 & 261.7 & +18.2 \\
150 & 2040 & 266.0 & +21.6 \\
200 & 1535 & 267.1 & +23.0 \\
250 & 1220 & 267.0 & +23.2 \\
300 & 2275 & 351.2 & +3.6 \\
350 & 1420 & 348.2 & +5.4 \\
400 & 1010 & 343.5 & +7.4 \\
500 & 1360 & 349.1 & +5.4 \\
600 & 630 & 339.2 & +10.7 \\
800 & 562 & 344.4 & +3.9 \\
1000 & 353 & 338.1 & +2.5
\end{tabular}

332B-36-3, 123-135 (6A) DP DP

$\begin{array}{rrrr}0 & 4140 & 43.9 & +2.4 \\ 25 & 4120 & 42.5 & +2.5 \\ 50 & 4250 & 39.8 & +1.9 \\ 100 & 4280 & 42.0 & +2.1 \\ 150 & 3950 & 43.1 & +2.7 \\ 200 & 3690 & 42.2 & +2.3 \\ 250 & 3170 & 42.4 & +2.9 \\ 300 & 2755 & 39.2 & +2.8 \\ 400 & 2265 & 41.0 & +2.0 \\ 500 & 1650 & 43.9 & +3.6 \\ 600 & 1275 & 43.5 & +4.0 \\ 800 & 844 & 44.0 & +3.8 \\ 1000 & 488 & 39.6 & -8.5\end{array}$

335-8-4, 14-26 (P1B) DP DP

\begin{tabular}{rrrr}
0 & 4630 & 21.0 & -54.8 \\
25 & 4620 & 27.6 & -54.2 \\
50 & 4660 & 21.9 & -53.4 \\
100 & 4670 & 21.1 & -55.4 \\
150 & 4690 & 20.6 & -54.1 \\
200 & 4620 & 20.0 & -54.5 \\
250 & 4300 & 20.7 & -53.7 \\
300 & 4040 & 25.3 & -52.5 \\
400 & 3200 & 20.5 & -53.5 \\
500 & 2540 & 18.9 & -52.7 \\
600 & 2050 & 19.5 & -53.5 \\
800 & 1275 & 18.3 & -51.5 \\
1000 & 897 & 19.1 & -47.3 \\
\hline
\end{tabular}

Note: Results above 250 oersteds are likely spurious. The apparent intensity increase and jump in D are artifacts occasionally generated by the Digico magnetometer.

ized. but some normal magnetizations occur. Some normally magnetized cores are obviously viscous (e.g., 332B-11-1, 11-4), others, however, are not (e.g., 332B36-3, 46-2). On AF demagnetization, both 11-4 and 363 retain positive inclinations to 800 oe, while $11-1$ and 46-2 change to negative inclinations during thermal demagnetization. On this evidence, it is difficult to decide whether the reversals are real or a result of VRM during the present polarity epoch. The effect, in either case, is to reduce the magnetic anomaly. Samples from Site 335 are reversely magnetized with inclinations of $-42^{\circ}$ to $-55^{\circ}$.

\section{UNSTABLE MAGNETIZATION}

VRM Decay $-20^{\circ} \mathrm{C}$ to $200^{\circ} \mathrm{C}$

The relaxation times examined in laboratory VRM experiments vary from seconds to days, or at the most months. The usual method of assessing the effect of VRM over the $10^{6} \mathrm{yr}$ duration of a polarity epoch is to extrapolate from the laboratory viscosity coefficient, $S$, using the experimental relationship

$$
J_{r}(t)=J_{r}\left(t_{o}\right)+S\left(\log t-\log t_{o}\right)
$$

where $J_{r}$ is remanence measured at $t$ or $t_{o}$. This is an uncertain procedure because $S$ is not constant, but depends on the distribution of relaxation times $\tau$ for a particular sample.

It is a simple matter to activate the appropriate range of $\tau$ by taking advantage of the fact that $\tau$ is temperature dependent. Since

$$
\tau \mid \propto \exp [\text { const } K(T) / T]
$$

(Neel, 1949), where the anisotropy constant $K$ decreases with temperature $T$, i.e., very large values of $\tau$ at $20^{\circ} \mathrm{C}$ are accessible in a VRM experiment carried out only slightly above room temperature.

Table 5 lists viscosity coefficients determined by measuring the time decay of a VRM acquired by $10 \mathrm{~min}$ exposure to a 2-oe field at temperatures of $20^{\circ} \mathrm{C}$ to $200^{\circ} \mathrm{C}$. Almost invariably $S$ increases with temperature. In some samples, $S$ peaks at $75^{\circ}-100^{\circ} \mathrm{C}$. An example is shown in Figure 1, where the lines join values of VRM measured at equal decay times in the range 10$300 \mathrm{sec}$. (The actual experiments covered a much broader time scale.) The peak is a Hopkinson effect, reflecting the low Curie temperatures of these samples (cf. Figure 2).

\section{Enhancement of VRM and Susceptibility}

A peak in $S$ at these temperatures indicates an abundance of relaxation times in the range $10^{5}-10^{6} \mathrm{yr}$ compared to those in the sec to $\mathrm{yr}$ range. Viscous magnetic effects are therefore accelerated over the time of a polarity epoch relative to extrapolations from laboratory data.

A Hopkinson peak in $S$ implies a peak in susceptibility at similarly low temperatures. Dunlop (1974) has suggested thermal enhancement of induced magnetization in the deep continental crust as a source of regional magnetic anomalies. Although submarine basalts usually have a high $Q$ (remanent/induced magnetization ratio), a similar enhancement of susceptibility could be significant for hot basaltic magma rising at a ridge axis and could in part explain why axial anomalies tend to be high compared to the other magnetic stripes.

\section{MAGNETIC MINERALS AND DOMAIN STRUCTURE}

\section{Hysteresis Measurements}

Near-saturation hysteresis was measured for the 10 samples whose VRM at $200^{\circ} \mathrm{C}$ had previously been in- 
TABLE 2

Hysteresis, NRM, and Viscosity Data

\begin{tabular}{|c|c|c|c|c|c|c|c|c|c|c|c|c|c|}
\hline $\begin{array}{c}\text { Sample } \\
\text { (Core-Section) }\end{array}$ & $\begin{array}{c}J_{\text {nrm }} \times 10^{6} \\
(1-\text { axis })\end{array}$ & $\left(J_{s}\right)_{0}$ & $\begin{array}{c}S_{o} / J_{s o} \\
\times 10^{6}\end{array}$ & $\begin{array}{c}S_{100 / J_{\text {so }}} \\
\times 10^{6}\end{array}$ & $\widetilde{H}_{1 / 2}$ & $\left(H_{c}\right)_{o}$ & $\left(\mathrm{H}_{c}\right)_{200}$ & $\left(H_{c r}\right)_{O}$ & $\left(H_{c r}\right)_{200}$ & $\left(\frac{H_{c r}}{H_{c}}\right)_{o}$ & $\left(\frac{H_{c r}}{H_{c}}\right)_{200}$ & $\left(\frac{J_{r s}}{J_{s}}\right)_{o}$ & $\left(\frac{J_{r s}}{J_{s}}\right)_{200}$ \\
\hline \multicolumn{14}{|l|}{ Hole 332B } \\
\hline $2-1$ & 755 & 3.69 & 2.1 & - & 350 & 261 & 80 & 445 & 153 & 1.70 & 1.92 & 0.385 & 0.192 \\
\hline $3-1$ & 20 & 4.92 & 1.6 & 3.2 & 35 & 110 & 79 & 180 & 153 & 1.64 & 1.95 & 0.244 & 0.169 \\
\hline $11-2$ & 840 & 1.86 & 23.4 & $\begin{array}{c}132.0 \\
\left(75^{\circ} \mathrm{C}\right)\end{array}$ & 34 & 13 & 47 & 80 & 109 & 6.12 & 2.32 & 0.012 & 0.136 \\
\hline $11-4$ & 37 & 1.80 & 3.5 & 40.2 & 135 & 88 & 180 & 158 & 284 & 1.80 & 1.58 & 0.220 & 0.403 \\
\hline $29-1$ & 825 & 1.53 & 4.1 & 15.6 & 245 & 81 & 83 & 146 & 128 & 1.80 & 1.54 & 0.201 & 0.263 \\
\hline $36-3$ & 79 & 0.93 & 3.3 & 6.8 & 412 & 216 & 296 & 585 & 501 & 2.71 & 1.69 & 0.290 & 0.512 \\
\hline $44-6$ & 640 & 2.13 & 12.5 & 75.8 & 42 & 39 & 80 & 145 & 157 & 3.72 & 1.96 & 0.113 & 0.196 \\
\hline \multicolumn{14}{|l|}{ Site 334} \\
\hline $20-2$ & 345 & 0.53 & 5.8 & 14.7 & 350 & 163 & 153 & 230 & 195 & 1.41 & 1.27 & 0.443 & 0.408 \\
\hline \multicolumn{14}{|l|}{ Site 335} \\
\hline $6-1$ & 2940 & 3.72 & 0 & 0 & 685 & 214 & 325 & 450 & 467 & 2.10 & 1.44 & 0.354 & 0.437 \\
\hline $8-4$ & 3130 & 5.10 & 1.8 & 6.7 & 538 & 333 & 210 & 435 & 324 & 1.30 & 1.54 & 0.506 & 0.452 \\
\hline $10-1$ & 3180 & 5.61 & $?$ & ? & $?$ & 232 & & 425 & & 1.83 & & 0.231 & \\
\hline
\end{tabular}

Note: Hysteresis was measured on virgin material and again after heating in air to $200^{\circ} \mathrm{C}$. All magnetizations are in emu $\mathrm{cm}^{-3}$ and fields in oersteds. Symbols defined in the text. 1 - axis refers to long axis only.

vestigated using a ballistic magnetometer and a 2300 oe solenoid. For comparison, saturation hysteresis was measured using virgin chips of the same samples with a PAR vibrating-sample magnetometer in the 20,000 oe field of an electromagnet. Table 1 lists values of saturation magnetization $J_{s}$, coercive force $H_{c,}$, remanent coercive force $H_{c r}$, saturation remanence ratio $J_{i r s} / J_{i s}$ and coercivity ratio $H_{c r} / H_{c}$, as well as $20^{\circ} \mathrm{C}$ and $100^{\circ} \mathrm{C}$ viscosity coefficients normalized to $J_{i s}$. Hysteresis parameters, particularly $H_{c}, J_{r s} / J_{s}$, and $H_{c r} / H_{c}$, have diagnostic value in determining domain structure (see e.g., Nagata et al., 1972; Gose et al., 1972). Very low values of $J_{r s} / J_{s}$, for example in 332B11-2 and 44-6, indicate multidomain structure. Values near 0.5 (e.g., 335-8-4 and 334-20-2) indicate singledomain grains. The other samples have either a mixture of single-domain and multidomain material or else grain sizes in the pseudo-single-domain range (0.05-20 $\mu \mathrm{m}$ in magnetite). These conclusions probably apply to the carriers of NRM because $H_{i c}$ correlates reasonably well with NRM median demagnetizing field $\widetilde{H}_{1 / 2}$.

\section{Thermomagnetic Analysis}

Figure 2 illustrates the various types of $J_{S}$ versus $T$ curves recorded with a PAR vibrating sample magnetometer. A few samples, of which 332B-44-6 is an example, exhibit a single low Curie temperature in the range $150^{\circ}-200^{\circ} \mathrm{C}$. Their thermomagnetic curves are nearly reversible upon cooling from $650^{\circ} \mathrm{C}$. To judge by the low Curie temperature, the magnetic phase is responsible in a high-titanium titanomagnetite. The multidomain hysteresis properties imply a grain size greater than $20 \mu \mathrm{m}$.

Most thermomagnetic curves are irreversible. The saturation magnetization increases after a heatingcooling cycle, often two or threefold. Some examples are 332B-29-1 and 335-17-1, 6-1 in Figure 2. Generally there is evidence for two distinct magnetic phases, a low Curie temperature phase evident in the heating curves and a higher Curie temperature phase whose amount increases irreversibly during heating above $350^{\circ}-400^{\circ} \mathrm{C}$ at the expense of the low $T_{c}$ phase. These samples have more single-domain-like hysteresis properties before and especially after heating (Table 1). That is, both magnetic phases have a finer grain size than the single phase in reversible samples.

The obvious explanation of the irreversible magnetic behavior is that initially homogeneous, moderate to high $\mathrm{Ti}$ titanomagnetites exsolve during heating to intergrown ilmenite and low $\mathrm{Ti}$, high Curie temperature titanomagnetite. However, in a few samples, of which 335-6-1 is representative, high $T_{c}$ and low $T_{c}$ phases are seen on both heating and cooling. Irreversible changes occur whether heatings are carried out at near atmospheric oxygen partial pressure or in a hard vacuum.

\section{Correlation of Curie Points, Hysteresis, and VRM}

Table 6 illustrates the strong correlation among thermomagnetic, hysteresis, and viscosity data. Type 1 materials (332B-11-1, 11-4, 44-6, for example) possess a single low Curie temperature, soft multidomain hysteresis, high room-temperature viscosity coefficients (relative to saturation magnetization), and Hopkinson-type VRM peaks just below the Curie point. The concentration of NRM at low blocking temperatures and relatively reversible thermomagnetic behavior make these preferred samples for paleointensity determination. Type 2 materials are magnetically harder; however, because much of the NRM is carried by the high $T_{c}$ phase whose blocking temperatures lie in the range where the sample alters irreversibly, these materials are less favorable for paleointensity determination.

\section{Determination of Magnetic Paleofield Intensity}

Paleointensity determination is made difficult in the samples examined as irreversible alteration takes place at not very elevated temperatures. Successful results 
TABLE 3

Storage Test - DSDP Leg 37 Basalts

\begin{tabular}{|c|c|c|c|}
\hline & $M \times 10^{6}$ & D & I \\
\hline \multicolumn{4}{|c|}{$332 \mathrm{~B}-11-1,115-118$ (2) DP DP } \\
\hline NRM before & 1690 & 305.0 & +1 \\
\hline
\end{tabular}

332B-14-2, 84-86 (2) DP DP

\begin{tabular}{|c|c|c|c|}
\hline NRM before & 525 & 31.3 & -6.8 \\
\hline NRM after & 447 & 28.9 & -8.4 \\
\hline \multicolumn{4}{|c|}{ 332B-17-1, 6-8 (1) DP DP } \\
\hline NRM before & 3020 & 137.4 & -31 \\
\hline NRM after & 3610 & 143.9 & \\
\hline
\end{tabular}

332B-22-4, 74-77 (5F) DP DP

$\begin{array}{llrr}\text { NRM before } & 2040 & 224.7 & -34.1 \\ \text { NRM after } & 5760 & 221.0 & -9.9\end{array}$

332B-27-2, 101-103 (7D) DP DP

$\begin{array}{lrrr}\text { NRM before } & 935 & 263.9 & -1.4 \\ \text { NRM after } & 1035 & 261.9 & -4.9\end{array}$

332B-33-1, 127-130 (1) P13 DP DP

$\begin{array}{llll}\text { NRM before } & 1540 & 25.5 & -11.8\end{array}$

332B-46-2, 32-34 DP DP

$\begin{array}{llll}\text { NRM before } & 1955 & 33.7 & +4.7\end{array}$

$\begin{array}{llll}\text { NRM after } & 2115 & 30.8 & +3.5\end{array}$

333-26-1, 141-143 P18 DP DP

$\begin{array}{llll}\text { NRM before } & 1430 & 281.3 & -21.6 \\ \text { NRM after } & 1472 & 277.5 & -21.8\end{array}$

335-7-1, 85-87 (3B) DP DP

$\begin{array}{llll}\text { NRM before } \quad 2510 & 135.0 & -48.4\end{array}$

$\begin{array}{llll}\text { Nrm after } & 4075 & 128.1 & -58.1\end{array}$

335-8-2, 24-26 (3) DP DP

$\begin{array}{llll}\text { NRM before } & 2030 & 8.5 & -50.4 \\ \text { NRM after } & 2643 & 3.1 & -57.9\end{array}$

335-10-1, 22-24 (1E) DP DP

$\begin{array}{llll}\text { NRM before } & 2050 & 62.9 & -42.6 \\ \text { NRM after } & 3903 & 62.7 & -67.7\end{array}$

335-12-3, 132-134 (7A) DP DP

\begin{tabular}{llll} 
NRM before & 1720 & 27.8 & -47.8 \\
NRM after & 2608 & 21.2 & -57.5 \\
\hline
\end{tabular}

Note: Samples were stored 2 months with their vertical up $\left(\mathrm{I}=-90^{\circ}\right)$ axes in the direction and sense of the present Earth's field. NRM measured before and after storage.

aThe core itself is labelled 332B-37-1.
TABLE 4

Thermal Demagnetization of DSDP Leg 37 Basalts

\begin{tabular}{crrr} 
Temperature & $M \times 10^{6}$ & $\mathrm{D}$ & $\mathrm{I}$ \\
\hline 332B-11-1, 114-118 (2) DP DP \\
20 & 1602 & 304.7 & -7.1 \\
75 & 1359 & 300.4 & -3.1 \\
125 & 910 & 298.4 & +6.7 \\
175 & 640 & 298.8 & -11.9 \\
200 & 695 & 298.5 & -2.4 \\
250 & 863 & 294.2 & -5.9
\end{tabular}

332B-14-2, 84-86 (2) DP DP

$\begin{array}{rrrr}20 & 384 & 326.5 & -0.3 \\ 75 & 408 & 324.8 & -11.2 \\ 125 & 424 & 327.9 & -10.6 \\ 175 & 408 & 334.8 & -15.0 \\ 200 & 589 & 325.8 & +35.5 \\ 250 & 511 & 330.2 & +26.7\end{array}$

332B-22-4, 75-77 (5F) DP DP

$\begin{array}{rrrr}20 & 4980 & 222.4 & -10.9 \\ 100 & 4920 & 222.0 & -10.8 \\ 175 & 4840 & 222.5 & -8.8 \\ 250 & 6540 & 222.3 & -10.9 \\ 300 & 4900 & 222.9 & -4.0\end{array}$

332B-27-2, 101-103 (7D) DP DP

$\begin{array}{rrrr}20 & 885 & 265.7 & -2.5 \\ 75 & 839 & 265.7 & -2.6 \\ 125 & 781 & 268.4 & -4.8 \\ 175 & 771 & 274.4 & -9.7 \\ 200 & 730 & 274.2 & +1.0 \\ 250 & 652 & 280.0 & -16.0\end{array}$

332B-33-1, 127-130 (1) P13 DP DP ${ }^{\mathrm{a}}$

$\begin{array}{rrrr}20 & 1183 & 27.1 & -31.9 \\ 75 & 1160 & 29.0 & -33.0 \\ 125 & 1125 & 27.3 & -32.9 \\ 175 & 908 & 24.8 & -18.8 \\ 200 & 798 & 33.1 & -26.4 \\ 250 & 646 & 30.4 & -39.1\end{array}$

332B-46-2, 32-34 DP DP

$\begin{array}{rrrc}20 & 821 & 43.1 & -67.2(?) \\ 50 & 1705 & 30.3 & -9.3 \\ 100 & 11,140 & 283.7 & +80.7(?)\end{array}$

$335-7-1,85-87$ (3B) DP DP

$\begin{array}{rlll}20 & 3400 & 144.7 & -62.0 \\ 50 & 3380 & 141.1 & -59.8 \\ 100 & 2850 & 180.0 & +85.5(?)\end{array}$

$335-10-1,22-24$ (1E) DP DP

$\begin{array}{llll}20 & 3450 & 64.9 & -67.0 \\ 75 & 3350 & 66.2 & -66.2 \\ 125 & 3325 & 64.7 & -67.9 \\ 175 & 2705 & 64.8 & -67.6 \\ 200 & 2715 & 63.7 & -65.8 \\ 250 & 2980 & 64.9 & -66.0\end{array}$

${ }^{\mathrm{a}}$ The core itself is labelled 37-1. 
TABLE 5

Magnetic Viscosity Coefficients Measured at Various Temperatures

\begin{tabular}{crrrrrr}
\hline Sample & \multicolumn{6}{c}{$\mathrm{S} \times 10^{6}\left(\mathrm{emu} \mathrm{cm}^{-3}\right.$ logcycle } \\
(Core-Section) & $20^{\circ} \mathrm{C}$ & \multicolumn{1}{c}{$50^{\circ} \mathrm{C}$} & \multicolumn{1}{c}{$75^{\circ} \mathrm{C}$} & $100^{\circ} \mathrm{C}$ & $150^{\circ} \mathrm{C}$ & $200^{\circ} \mathrm{C}$ \\
\hline Hole 332B & & & & & & \\
$2-1$ & 7.8 & 7.8 & 7.8 & - & - & - \\
$3-1$ & 7.9 & 11.0 & - & 15.7 & 26.7 & 47.6 \\
$11-2$ & 43.5 & 210.8 & 245.8 & 137.5 & 49.5 & 83.3 \\
$11-4$ & 6.3 & 9.4 & 34.3 & 72.4 & 25.7 & 18.6 \\
$29-1$ & 6.3 & 14.1 & 17.3 & 23.9 & 34.9 & 18.6 \\
$36-3$ & 3.1 & 9.4 & 11.0 & 6.3 & - & - \\
$44-6$ & 26.7 & 90.4 & 114.4 & 161.4 & 58.0 & 22.3
\end{tabular}

Site 334

$$
3 .
$$

Site 335

$\begin{array}{lllcccc}6-1 & 0 & 0 & 0 & 0 & 0 & 0 \\ 8-4 & 9.4 & 9.4 & 20.7 & 34.3 & 32.5 & 20.7\end{array}$

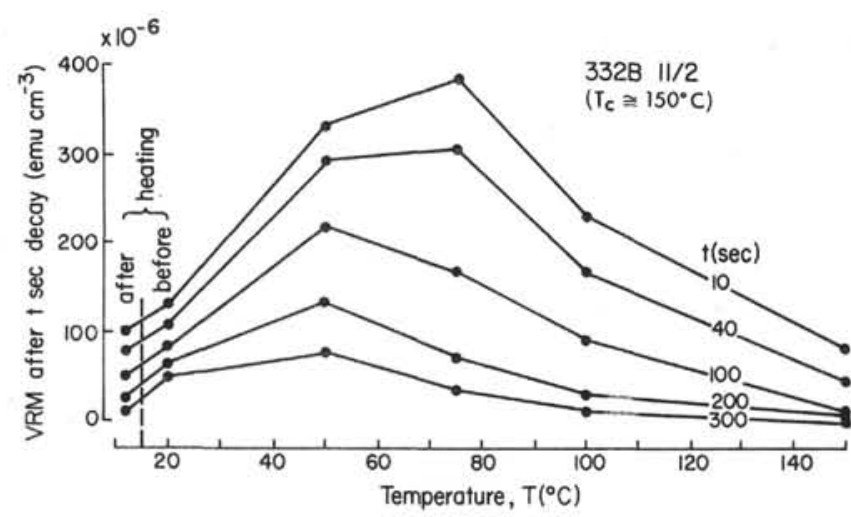

Figure 1. VRM as a function of decay time and temperature for Sample 332B-11-2. VRM's were produced at the temperatures indicated by $10 \mathrm{~min}$ exposure to a 2-oe field. VRM is acquired (and decays) very rapidly at $75^{\circ} \mathrm{C}$, just below the Curie temperature of this sample (Hopkinson effect). The vertical dashed line indicates the estimated in-situ temperature $\left(14.5^{\circ} \mathrm{C}\right)$ at the depth where 332B-11-2 was sampled. were obtained, however, for five samples using the method of Thellier and Thellier (1959). Samples were alternately heated to successively higher temperatures in a zero field and in a laboratory field applied along the vertically up axis. After each heating the sample was remeasured with a PAR SM2B spinner magnetometer. Zero field was held to less than a few gammas and the applied field to $5 \times 10^{4}$ gammas by means of a molypermalloy shielded room containing a triaxial Helmholtz feedback balancing system. Samples were heated in a vacuum of less than $10^{-5}$ torr. Temperatures in companion heatings were reproduced accurately by means of a Hewlett-Packard temperature programmer.

Paleointensity data for the five samples (332B-11-1, $22-4,27-2,33-1 ; 335-10-1)$ are presented in Table 4. NRM lost is plotted against PTRM (partial thermoremanent magnetization) gained in Figure 3.

Despite the hard vacuum, chemical alteration was observed at varying temperatures in all five samples. The five samples may be broadly divided into two categories: those (332B-11-1, 33-1; 335-10-1) which appear to be stable to only $175^{\circ} \mathrm{C}$ and those (332B-22-4, 27-2) which remain stable up to $250^{\circ} \mathrm{C}$. Indicated values of $H$ tend to be lower for samples which show alteration at lower temperatures. This may result in part from artificially high PTRM's resulting from formation of secondary magnetite by exsolution upon heating. Samples in the higher stability category (332B$22-4,27-2$ ) indicate paleointensities which approach more closely the present earth's field intensity. It should be noted that directions for these samples remain stable well after the intensities have become unreliable.

Low oxidation state titanomagnetites present a challenge for paleointensity work because, with reasonable temperature intervals $\left(50^{\circ} \mathrm{C}\right.$ or so), few reliable points result and these represent only the initial portion of the normal Thellier-Thellier plot, particularly for Type 2, highly alterable materials. Type 1 materials, on the other hand, possess a concentration of low Curie temperatures and a high susceptibility to viscous magnetization which would ordinarily lead them to be considered unsuitable for paleointensity work.

TABLE 6

Correlations Among Hysteresis, NRM, Viscosity, and Thermomagnetic Data

\begin{tabular}{|c|c|c|c|c|c|c|c|c|c|}
\hline Hole & $\begin{array}{c}\text { Sample } \\
\text { (Core-Section) }\end{array}$ & $\left(H_{c}\right)_{o}$ & $\left(\frac{H_{c r}}{H_{c}}\right)_{o}$ & $\left(\frac{J_{r s}}{J_{s}}\right)_{o}$ & $\widetilde{H}_{1 / 2}$ & $\frac{S_{o}}{\left(J_{S}\right)_{o}} \times 10^{6}$ & $\frac{S_{100}}{S_{o}}$ & $\frac{\left(J_{s}\right)_{600}}{\left(J_{s}\right)_{O}}$ & Curie Temperatures \\
\hline 332B & $11-2$ & 13 & 6.12 & 0.012 & 34 & 23.4 & $5.65^{*}$ & 1.03 & $\approx 150(\mathrm{~h}, \mathrm{c})$ \\
\hline $332 \mathrm{~B}$ & 44-6 & 39 & 3.72 & 0.113 & 42 & 12.5 & 6.05 & 1.18 & $160-180(\mathrm{~h}, \mathrm{c})$ \\
\hline $332 \mathrm{~B}$ & $29-1$ & 81 & 1.80 & 0.201 & 245 & 4.1 & 3.80 & 1.48 & $220-260$ (h) $400-450(\mathrm{~h}, \mathrm{c})$ \\
\hline 332B & $11-4$ & 88 & 1.80 & 0.220 & 135 & 3.5 & 11.50 & 1.26 & $150-200(\mathrm{~h}, \mathrm{c})$ \\
\hline $332 \mathrm{~B}$ & $3-1$ & 110 & 1.64 & 0.244 & 35 & 1.6 & 2.00 & 1.51 & $250-300(\mathrm{~h}, \mathrm{c}) 480-500(\mathrm{~h}, \mathrm{c})$ \\
\hline 334 & $20-2$ & 163 & 1.41 & 0.443 & 350 & 5.8 & 2.55 & 1.60 & $250-300(\mathrm{~h}) 450-480(\mathrm{c})$ \\
\hline 335 & $6-1$ & 214 & 2.10 & 0.354 & 685 & 0 & - & 3.64 & $250-300(\mathrm{~h}, \mathrm{c}) 500-520(\mathrm{~h}, \mathrm{c})$ \\
\hline 332B & $36-3$ & 216 & 2.71 & 0.290 & 412 & 3.3 & 2.05 & 2.12 & $\begin{array}{l}\text { broad range }(\mathrm{h}) \\
\approx 150 \text { (c) } 440-460 \text { (c) }\end{array}$ \\
\hline $332 \mathrm{~B}$ & $2-1$ & 261 & 1.70 & 0.385 & 350 & 2.1 & - & 2.83 & $250-300$ (h) $500-550$ (c) \\
\hline 335 & $8-4$ & 333 & 1.30 & 0.506 & 538 & 1.8 & 3.70 & 2.48 & $240-260$ (h) $450-490$ (c) \\
\hline
\end{tabular}

Note: $\mathrm{h}=$ heating; $\mathrm{c}=$ cooling; ${ }^{*}=\mathrm{S}_{75} / \mathrm{S}_{0}$. All magnetizations are in emu $\mathrm{cm}^{-3}$, all fields are in oersteds, Curie temperaltures are in ${ }^{\circ} \mathrm{C}$. Symbols defined in text. 

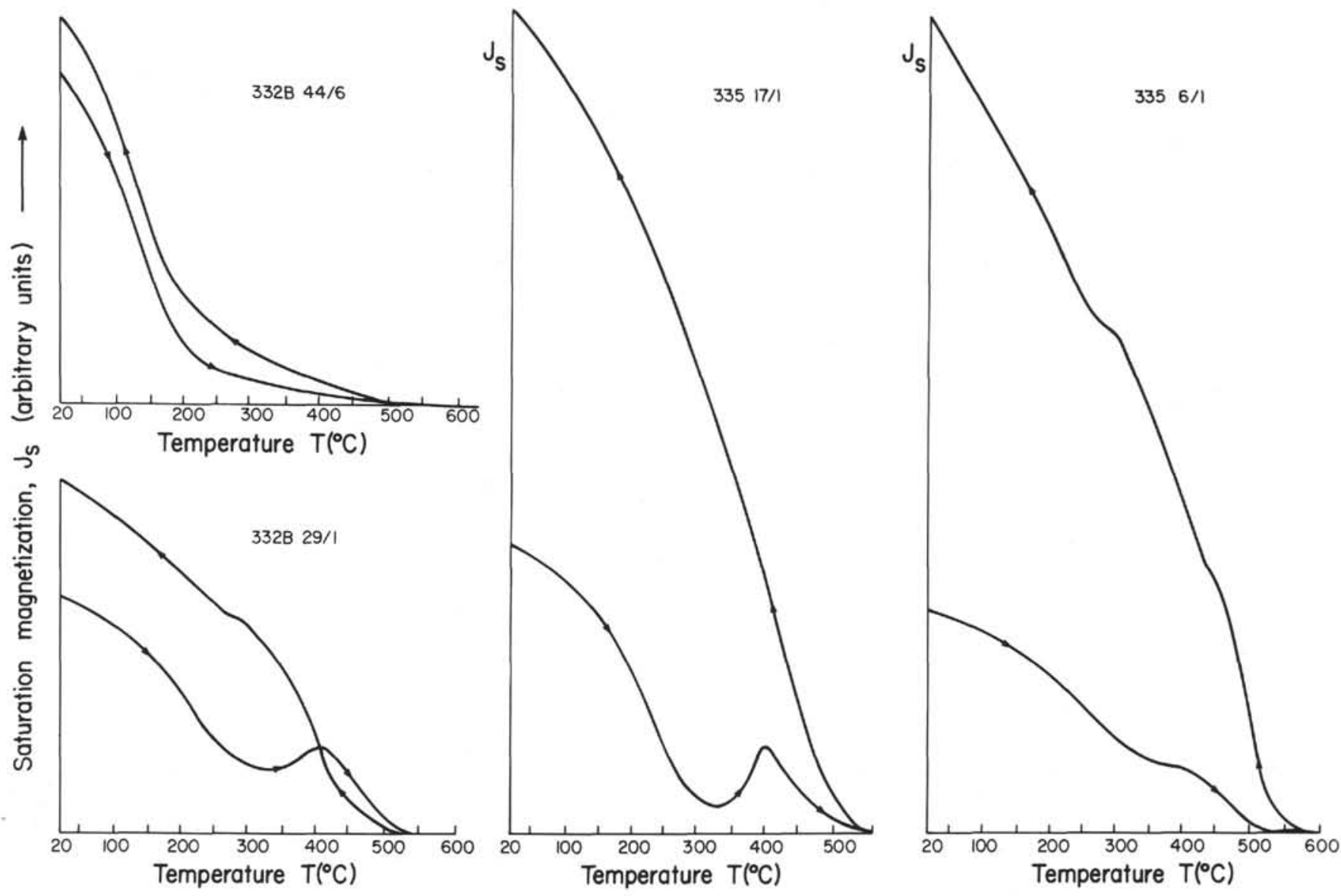

Figure 2. Typical thermomagnetic(saturation magnetization versus temperature) curves. Notice the reversible curve and single low Curie point of Sample 332B-44-6. This has been designated Class 1 behavior (see text). Production of a high Curie temperature phase during heating to $350^{\circ}-400^{\circ} \mathrm{C}$ is evident in both $332 \mathrm{~B}-29-1$, whose behavior is nearly reversible, and 335-17-1 which is highly reversible. 335-6-1 is unusual in that it shows two Curie points in both heating and cooling curves.

TABLE 7

Paleofield Intensity Determined by a Modified Thellier-Thellier Technique

\begin{tabular}{ccc}
\hline \multirow{2}{*}{ Sample } & Temperature & Paleofield Intensity \\
& Range Used $\left({ }^{\circ} \mathrm{C}\right)$ & $H_{a}(\mathrm{oe})$ \\
\hline
\end{tabular}

\section{Hole 332B}

$\begin{array}{lrr}11-1 & 20-200 & 0.10 \begin{array}{l}+0.22 \\ -0.02\end{array} \\ 22-4 & 20-175 & 0.35 \begin{array}{l}+0.05 \\ -0.08\end{array} \\ 27-2 & 20-200 & 0.45 \begin{array}{l}+0.08 \\ -0.07\end{array} \\ 33-1 & 20-175 & 0.12 \begin{array}{l}+0.0 \\ -0.02\end{array}\end{array}$

Site 335

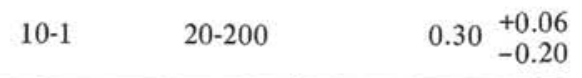

Note: The best estimate of $H_{a}$ is derived from least squares fitting to the data (Figure 3). Upper and lower bounds for $H_{a}$ are determined from lines of maximum and minimum slope through two or more of the data points.
Clearly any total TRM or ARM method of paleointensity determination which involves a single heating to high temperature would be completely unreliable in dealing with low-oxidation state submarine basalts.

\section{ACKNOWLEDGMENTS}

This research was supported by the National Research Council of Canada through a D.A.G.S. grant to D.J. Dunlop. We wish to thank G.W. Pearce and D.W. Strangway for the use of their laboratory equipment and for helpful advice on paleointensity determinations based on their experience with lunar materials.

\section{REFERENCES}

Dunlop, D.J., 1974. Thermal enhancement of magnetic susceptibility: J. Geophys., v. 40, p. 430-451.

Gose, W.A., Pearce, G.W., Strangway, D.W., and Larson, E.E., 1972. Magnetic properties of Apollo 14 breccias and their correlation with metamorphism: Third Lunar Sci. Conf. Proc., Geochim. Cosmochim. Acta, v. 3, p. 2387 2395.

Nagata, T., Fisher, R.M., and Schwerer, F.C., 1972. Lunar rock magnetism: The Moon, v. 4, p. 161-186.

Néel, L., 1949. Théorie du traînage magnétique des ferromagnétiques en grains fins avec applications aux terres cuites: Ann. Géophys., v. 5, p. 99-136. 

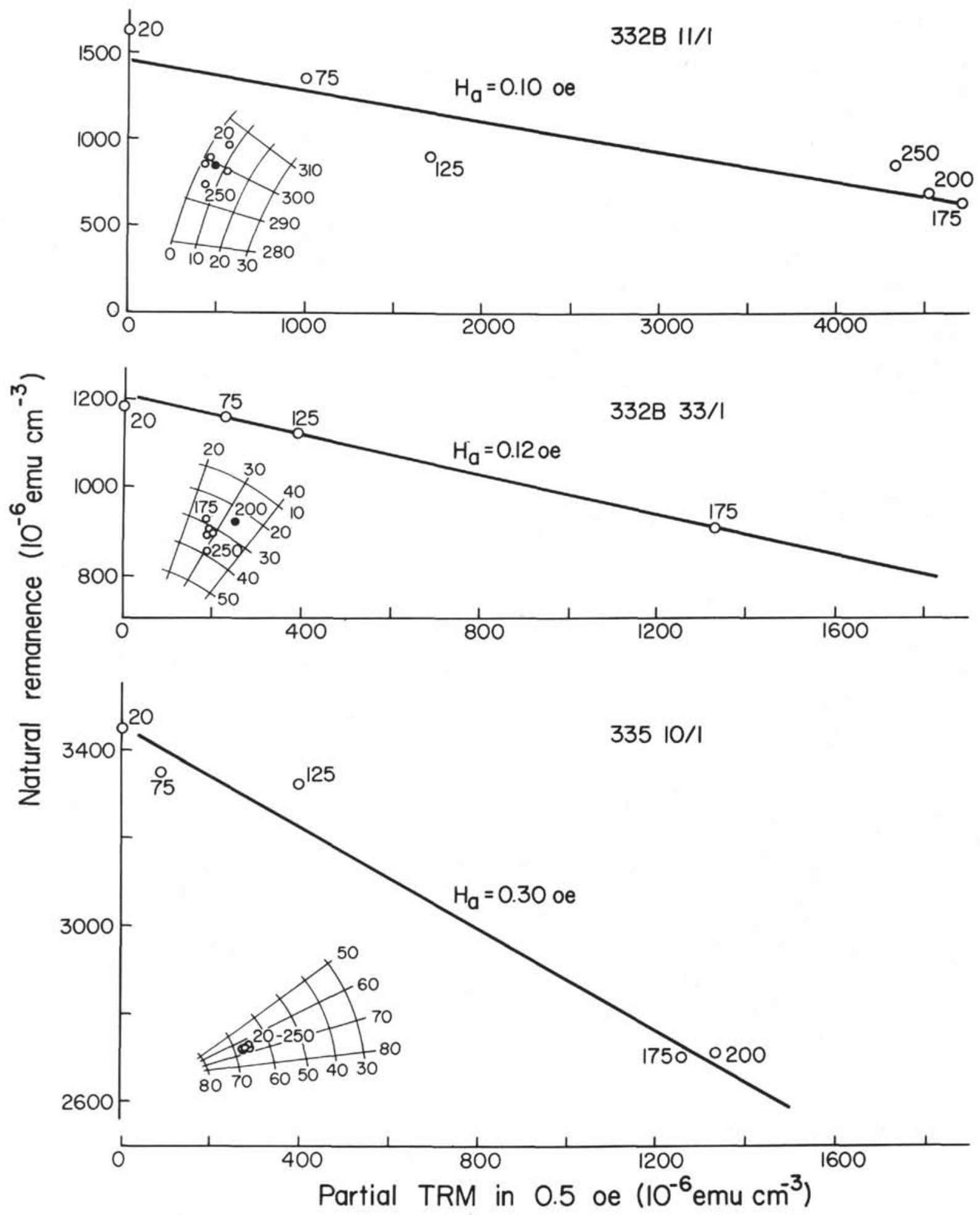

Figure 3. Thellier and Thellier-type paleointensity determinations. Directional data are plotted on equal-area projections with open circles for upwards or negative inclinations. Directions often remain stable above $175^{\circ}$ or $200^{\circ} \mathrm{C}$ even though chemical alteration has rendered intensity data unusable. The slope of the NRM/PTRM line is the paleofield/laboratory field ratio. The slopes have been converted into estimates of paleointensity $H_{a}$.

Thellier, E. and Thellier, O., 1959. Sur l'intensité du champ magnétique terrestre dans le passé historique et géologique: Ann. Géophys., v. 15, p. 275-376.
West, G.F. and Dunlop, D.J., 1971. An improved ballistic magnetometer for rock magnetic experiments: J. Sci. Instrum., v. 4, p. 37-40. 